\title{
The rate of corrosion of concrete reinforcement and possibilities of its mathematical modelling
}

\author{
V ŽIVICA \\ Institute of Construction and Architecture of the Slovak Academy of Sciences, Bratislava, \\ Slovak Republic
}

MS received 6 May 1994; revised 20 October 1994

\begin{abstract}
The paper describes a method for the mathematical modelling of steel reinforcement corrosion rate. This method is based exclusively on experimental results and expression of the influence of significant corrosion factors in the form of functional relations. The method takes into account the reality of the effects of corrosion factors, their contigency and complexity, and various circumstances occurring in practice. It represents one way towards the development of methods for the prediction of service life of reinforced concrete and structures.
\end{abstract}

Keywords. Concrete reinforcement corrosion; corrosion rate; corrosion factors; relative humidity; chloride concentration; mathematical modelling.

\section{Introduction}

The design of concrete structures is usually based on empirical relationships between material and properties of concrete and experience with the behaviour of building materials. A new approach of concrete design is based on the prediction of its service life. Though this approach is not often used it has increasing importance in the design of concrete. The motivating factors are the increasing air pollution in recent years, importance of energy and material saving, and last but not least the growing number of cases of damage in old concrete structures and rising demands to calculate the service life of reinforced concrete structures. The steadily increasing interest in the service life prediction of concrete structures is shown for example in the papers by Müller (1985), Masters (1986) and Eurin (1988).

One approach is to obtain quantitative values about service life of concrete structures for mathematical models based on the chemistry and physics of degradation processes (Clifton 1990). Several models have been developed for prediction of service life of concrete subjected to degradation processes. Atkinson developed a model for leaching degradation (Atkinson 1985). This author and Odler and Gasser (1988) developed a model based on the mechanism of sulphate attack. The range of usefulness of any mathematical model depends upon the adequacy of the conceptual models upon which it is based. The adequacy and the success of the modelling can be limited by the following factors: (i) problems of application of theoretical data and relationships to real, heterogeneous concrete systems and (ii) simplification of degradation processes and taking into consideration only some degradation rate factors. However, it is a well-known fact that deterioration rate of concrete is a result of the interaction of the aggressive of medium and resistance of concrete. These factors alone represent a set of several partial factors.

An approach exclusively based on experimental results of studies on the influence of individual factors of aggressivity of medium and concrete resistance on the corrosion 
rate allows the possibility of avoiding the shortcomings of modelling and increasing its usefulness. Morinaga (1990) chose this approach for prediction of service life of reinforced concrete structures.

Jambor's method also belongs to the category of mathematical modelling exclusively based on experimental results (Jambor et al 1983). According to this method the degree and rate of deterioration of concrete can be expressed as a product of functional relations, which themselves express the influence of the individual factors of destruction processes. The method represents an open system, which enables the gradual completion of the functional relations product. This is a significant point for preference of the method, because it enables increasing the capability for various circumstances that occur in practice.

It is assumed that for the utilization of the method in practice, at least a knowledge of the influence of the most important factors of deterioration process and its rate and the expression of their influence in corresponding functional relations are required.

The significance of corrosion of steel reinforcement in the service life of reinforced concrete is indisputable. For prediction of service life of reinforced concrete also several mathematical models have been developed. These models take into consideration the depassivation rate expressed by the penetration rate of aggressive substanceschlorides, $\mathrm{CO}_{2}$ or other aggressive gases--through the concrete cover to the reinforcement surface (Grunau 1970; Alekseev 1978). These models allow determination of the approximate time of depassivation of reinforcement or the initiation of its corrosion. However, information about the actual state of the reinforcement and corrosion rate is missing. This is an important shortcoming.

Knowledge of the character of reinforcement corrosion enables for its quantitative description and expression of corrosion rate a realistic parameter which represents the quantity of corroded steel. This parameter enables determination of a significant criterion for the state of reinforcement, the value of cross-section decrease of reinforcement, which represents an important parameter for evaluation of the service life of reinforcement concrete.

In connection with mathematical modelling and prediction of service life of reinforced concrete, attention is being increasingly paid to the utilization of electrochemical methods. On the basis of results with the so-called electrochemical cell a model of a two-step mechanism has been developed by Tuutti (1971) for corrosion of reinforcement steel in concrete.

The object of this paper is an attempt to model the rate of concrete reinforcement corrosion mathematically on the basis of experimental results.

\section{Experimental}

Mortar prisms $40 \mathrm{~mm} \times 40 \mathrm{~mm} \times 60 \mathrm{~mm}$ with embedded corrosion sensors for the improved method of electrical resistance measurement (IER method) were used for the study. The method was improved by developing a so-called "corrosion sensor". This sensor is embedded in the cement composite test specimen or in the concrete structure and enables one to check the condition of reinforcement. The structure of the sensors excludes disturbing effects during the measurement and increases the sensitivity of the method and the reliability of the test results. The method is described in detail elsewhere (Živica 1993). 
The composition of the mortars used was as follows: Portland cement: sand 1:3,w/c 0.6 , portions of $\mathrm{CaCl}_{2}$ admixture $0,1,2,4$ and $8 \%$ based on cement.

After moulding, the test specimens were cured for $24 \mathrm{~h}$ at relative humidity (RH) of $95 \%$. After this time the curing regime was as follows: a part of the test specimens were cured at $\mathrm{RH}$ of $95 \%$ and the rest at $\mathrm{RH}$ of 65 and $35 \%$. The temperature of curing was $20 \pm 2^{\circ} \mathrm{C}$.

The cement used was Portland cement class 400 according to the Standard CSN 722121 corresponding to the recommendation ISO-R597. The sand used was silica sand according to Standard CSN 721208 corresponding to the recommendation ISO/R 697-1968. For preparation of the corrosion sensors steel sheet Class 11373 according to Standard ČN 411373 was used.

For the study of corrosion rate of steel the IER method was used. Further the method of electrode potential using the calomel saturated reference electrode (SCE) was used (Yambor and Živica 1982).

\section{Results and discussion}

The values of changes of electrical resistance of sensors $(\Delta R)$ and their electrode potential (EP) and weight of mortar test specimens are given in table 1 . In table 2 the results of visual inspection of the corrosion sensors after the test are given. The test mortar prisms were crushed and the state of the embedded sensors was evaluated.

The results obtained show that EP values of the sensors at the beginning of the tests were in good relation to the mortar composition as indicated by the EP value of $-254 \mathrm{mV}$ (SCE), the corrosively passive state of steel in mortar without $\mathrm{CaCl}_{2}$ admixture, and by EP values of $-447,-491,-512$ and $-513 \mathrm{mV}$ (SCE), the corrosively active state of steel in mortars with $1,2,4$ and $8 \% \mathrm{CaCl}_{2}$ admixture respectively. With time the EP values decreased with good correlation between EP values and $\mathrm{CaCl}_{2}$ content in mortars. From the point of view of corrosion process of steel it is important to determine the duration of the corrosively active state of steel or of the EP values of the sensors in corrosively active range i.e. above -300 to $-350 \mathrm{mV}$ (SCE). The results show that in the mortar with $1 \% \mathrm{CaCl}_{2}$ admixture the corrosively active state existed for only a very short time of under 28 days. A highly passive EP value of $-240 \mathrm{mV}$ (SCE) was reached after 28 days of curing. In the mortars with 2 and $4 \% \mathrm{CaCl}_{2}$ admixture, the corrosively active state of steel lasted from 56 to 70 days, but with $\mathrm{CaCl}_{2}$ at $8 \%$ the corrosively active state remained throughout the duration of the test, i.e. 84 days, and EP was $-478 \mathrm{mV}$ (SCE) at the end of the test.

The obtained EP values are in good relation with the $\Delta R$ values. Increase in $\Delta R$ indicates steel corrosion in $\mathrm{CaCl}_{2}$ mortars with corrosively active EP values. The intensity of the increase in $\Delta R$ values or the corrosion rate of steel was proportionate to the level and duration in corrosively active range of EP values. It can be seen that with time the $\Delta R$ values of sensors embedded in mortars with $\mathrm{CaCl}_{2}$ admixture increased, indicating steel corrosion. The intensity of $\Delta R$ increased and curing time decreased.

Figure 1 confirms the role of relative humidity $(\mathrm{RH})$ in the electrochemical state of embedded steel and its corrosion rate. Below $\mathrm{RH} 65 \%$ corrosion rate is negligible, but above this value there is a significant increase in corrosion rate. The turning 


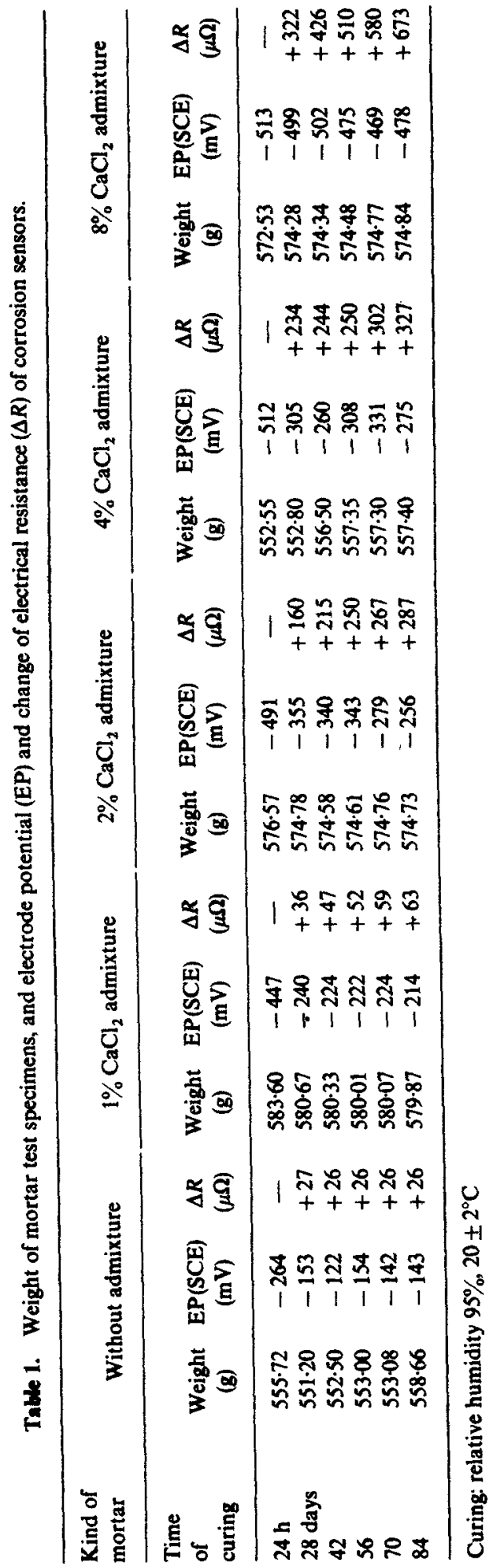


Table 2. Results of visual inspection of the corrosion sensors and final values of electrical resistance of the sensors.

\begin{tabular}{|c|c|c|c|c|}
\hline \multirow{3}{*}{$\begin{array}{l}\text { Relative humidity } \\
\text { (RH) and time } \\
\text { of curing }\end{array}$} & \multicolumn{4}{|c|}{ Kind of mortar } \\
\hline & \multicolumn{2}{|c|}{ Without admixture } & \multicolumn{2}{|c|}{$4 \% \mathrm{CaCl}_{2}$ admixture } \\
\hline & $\begin{array}{l}\text { Corroded } \\
\text { area }(\%)\end{array}$ & $\Delta R$ & $\begin{array}{l}\text { Corroded } \\
\text { area }(\%)\end{array}$ & $\Delta R$ \\
\hline $\begin{array}{l}\text { RH } 95 \% \\
644 \text { days }\end{array}$ & 3.5 & $\begin{array}{c}+38.7 \\
\text { (448 days) }\end{array}$ & 18 & +451 \\
\hline $\begin{array}{l}\text { RH } 65 \% \\
644 \text { days }\end{array}$ & 0 & -0.30 & 89 & +145 \\
\hline $\begin{array}{l}\text { RH } 35 \% \\
642 \text { days }\end{array}$ & 0 & $+0 \cdot 20$ & 30 & +45 \\
\hline
\end{tabular}

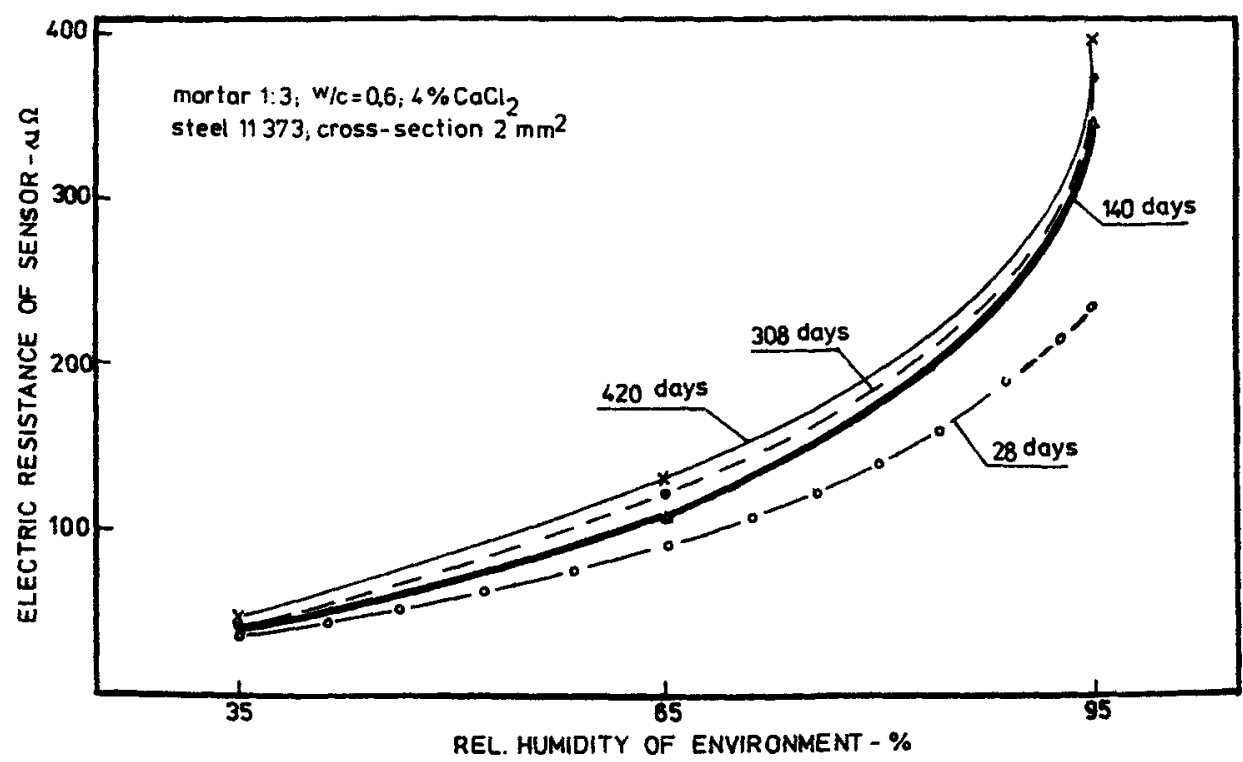

Figure 1. Relationship between electrical resistance of corrosion sensors and relative humidity of environment.

point around $\mathrm{RH}$ of $65 \%$ is in good accordance with the well-known $\mathrm{RH}$ values given elsewhere.

The influence of RH of environment on steel corrosion rate can be expressed by the functional relation (FR)

$$
F_{H}=e^{a_{h} e^{b_{h} H}},
$$

where $F_{H}$ is FR of degree of corrosion of steel in concrete with RH of the environment, $H$ is relative humidity of environment in $\%$, and $a_{h}, b_{h}$ are experimental coefficients. 
On the basis of the obtained experimental results, the following equation was obtained for the curve of 28 days in figure 1:

$$
F_{H}=e^{2.87 e^{0.0068 "}} .
$$

The course of the marked curves in figure 2, expressing the dependence of $\Delta R$ values on curing time, can be expressed by the functional relation

$$
F_{T}=a_{T} T^{b T}
$$

where $F_{T}$ is FR of degree of corrosion of steel with curing time of concrete in the given environment. $T$ is curing time (days), and $a_{T}$ and $b_{T}$ are experimental coefficients. This FR was expressed as a supplementary coefficient for the $F_{H}(1)$. After the numbering of the functional relation (3), the following equation was obtained for the curve for $\mathbf{R H}$ value of $95 \%$ in figure 2 :

$$
F_{T}=0.50 T^{0 \cdot 21} \text {. }
$$

The dependence of $\Delta R$ values of sensors on $\mathrm{CaCl}_{2}$ content in mortar is shown in figure 3 . This is given by the functional relation

$$
F_{C}=\frac{C}{a_{c}+b_{c} C}+c_{c},
$$

where $C$ is the proportion of $\mathrm{CaCl}_{2}$ admixture in mortar expressed in percentage, based on cement content, and $a_{c}, b_{c}, c_{c}$ are experimental coefficients.

After the numbering of function relation (5), the following equation was obtained

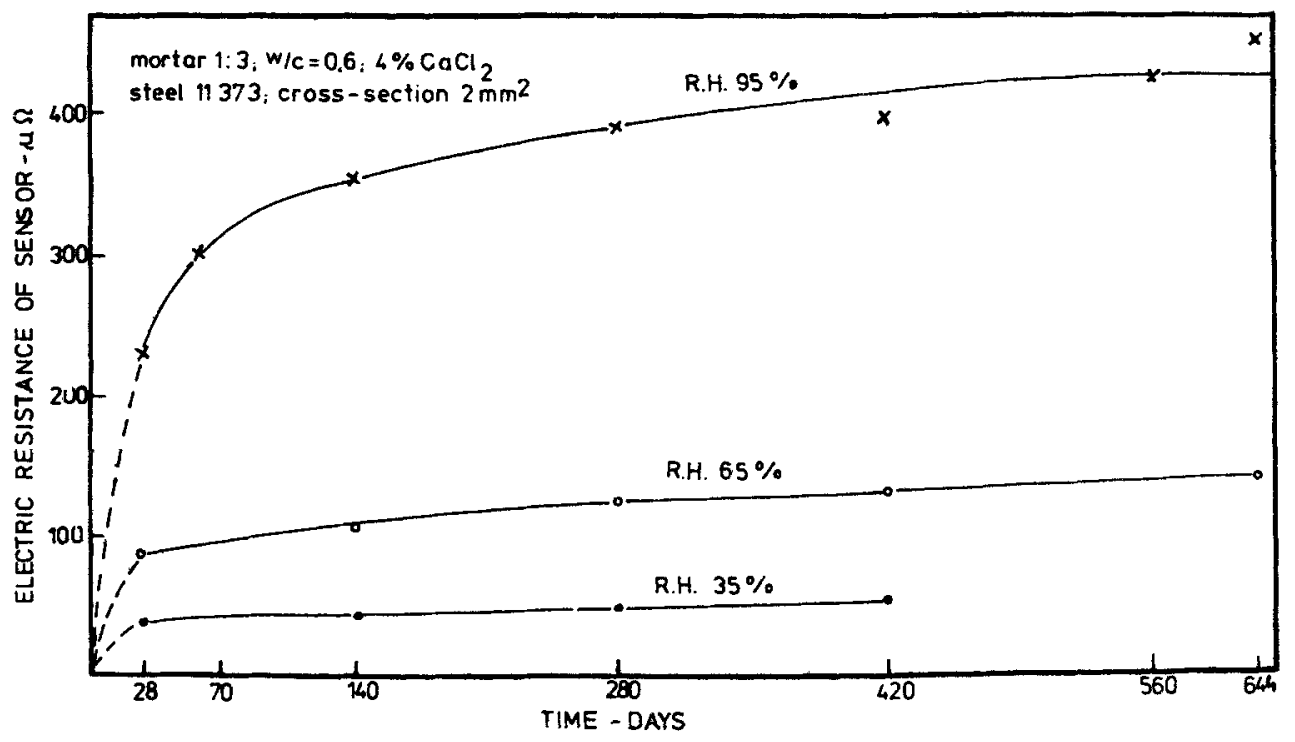

Figure 2. Relationship between electrical resistance of corrosion sensors and time of curing of the test specimens. 


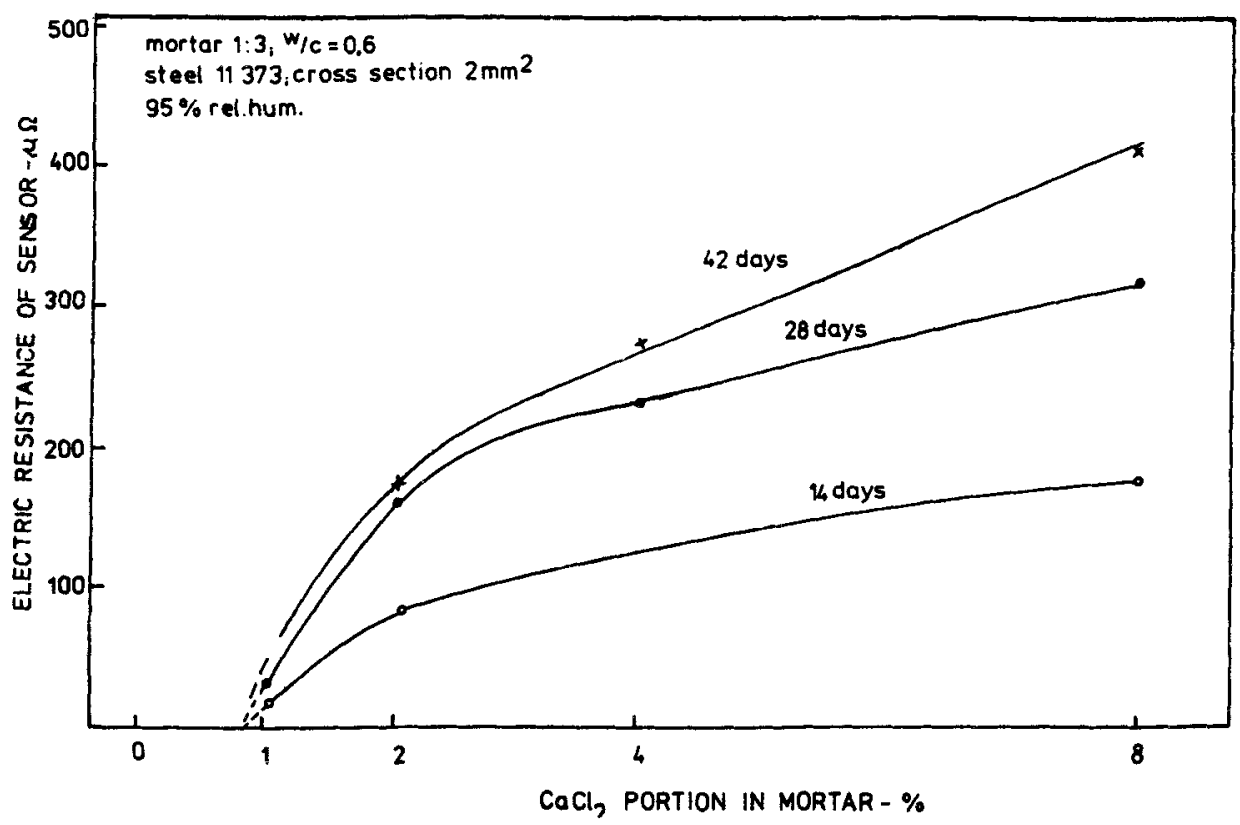

Figure 3. Relationship between electrical resistance of corrosion sensors and $\mathrm{CaCl}_{2}$ proportion in mortar.

for the 28-day curve in figure 3 :

$$
F_{C}=\frac{C}{1 \cdot 80+0.45 C}-0 \cdot 15
$$

According to the principle of Jambor's method the degree of corrosion of steel reinforcement expressed as $\Delta R$ is given by the product of functional relations (1), (3) and (5):

$$
\begin{aligned}
\Delta R_{\mathrm{cal}} & =F_{H} \cdot F_{C} \cdot F_{T}, \\
& =e^{a_{h} e^{b} h^{H}} \cdot\left(\frac{C}{a_{c}+b_{c} C}+c_{c}\right) \cdot a_{T} T^{b T}, \\
& =e^{2.87 e^{0.0068^{H}}} \cdot\left(\frac{C}{1.80+0.45 C}-0 \cdot 15\right) \cdot 0.50 T^{0.21} .
\end{aligned}
$$

Table 3 gives the comparison of the experimental and calculated results according to (9). It can be seen that the results show some differences. The heterogeneity of steel corrosion process seems to be the main cause of the differences. Increasing the number of test specimens and frequency of measurement can probably reduce the differences and increase the adequacy of the mathematical modelling.

It is well known that corrosion causes reduction of the cross-section of steel reinforcement $(\Delta \mathrm{CS})$. This represents a danger for the safety of reinforced concrete or construction. It is possible to calculate this reduction on the basis of $\Delta R$ values 
Table 3. Calculated and experimental values of $\Delta R$ of sensors and $\mathrm{CaCl}_{2}$ proportion in mortar.

\begin{tabular}{|c|c|c|c|}
\hline \multirow[b]{2}{*}{ Time (days) } & \multicolumn{3}{|c|}{$\mathrm{CaCl}_{2}(\%)$} \\
\hline & 2 & 4 & 8 \\
\hline \multirow[t]{2}{*}{28} & $147^{*}$ & 234 & 353 \\
\hline & $\overline{160}$ & $\overline{234}$ & $\overline{322}$ \\
\hline \multirow[t]{2}{*}{56} & 170 & 270 & 408 \\
\hline & $\overline{250}$ & $\overline{250}$ & $\overline{510}$ \\
\hline \multirow[t]{2}{*}{$70^{\circ}$} & 178 & 283 & 425 \\
\hline & $\overline{267}$ & $\overline{302}$ & $\overline{570}$ \\
\hline \multirow[t]{2}{*}{140} & 205 & 326 & 492 \\
\hline & - & $\overline{354}$ & $\overline{-}$ \\
\hline \multirow[t]{2}{*}{308} & 242 & 384 & 580 \\
\hline & - & $\overline{388}$ & $\overline{-}$ \\
\hline \multirow[t]{2}{*}{420} & 258 & 409 & 618 \\
\hline & - & $\overline{397}$ & - \\
\hline \multirow[t]{2}{*}{644} & 282 & 447 & 675 \\
\hline & - & $\overline{451}$ & - \\
\hline
\end{tabular}

estimated by IER method:

$$
\Delta \mathrm{CS}=\frac{\mathrm{CS} \cdot \Delta R}{R_{0}}
$$

where CS is initial cross-section of the steel of the sensor and $R_{0}$ its initial electrical resistance.

From a practical point of view, to predict the service life of reinforced concrete materials in aggressive environments it is important to know the time $T_{\text {cr }}$ which represents the time when the critical value of the cross-section reduction of reinforcement $\Delta \mathrm{CS}_{\mathrm{cr}}$ or the related $\Delta R_{\mathrm{cr}}$, is reached. Using (7) and (8) it is possible to calculate $T_{\mathrm{cr}}$ :

$$
T_{\mathrm{cr}}=\left(\frac{\Delta R_{\mathrm{cr}}}{a_{T} \cdot F_{H} \cdot F_{C}}\right)^{1 / b T},
$$

when $\Delta R_{\mathrm{cr}}$ is given by the critical value of cross-section reduction of reinforcement.

\section{Conclusions}

1. The experimental process and mathematical modelling described the allow evaluation of the rate of corrosion of concrete reinforcement and service life of reinforced concrete materials under conditions that occur in practice. 
2. A precondition for application of the mathematical modelling is knowledge of the functional relations expressing the influence of the aggressive environmental factors and the resistance of reinforced concrete. These factors include concentration of aggressive components, relative humidity, temperature, reinforced concrete quality (concrete porosity, thickness of concrete cover, kind of reinforcement steel, etc.) Obtaining the functional relations requires experimental study. By increasing the number of functional relations the efficiency of the modelling method can be increased.

3. In this paper it has been shown the possibility of the expression of the influence of relative humidity of environment, chloride concentration in mortar and time of the existence of reinforced material in given circumstances in the form of functional relations. Using these relations the possibility of calculation of rate of corrosion of concrete reinforcement and service life of reinforced concrete materials also has been shown.

4. It must be emphasized that the results of the IER method are of effective value. This is highlighted by the well-known uneven damage developed along corroding concrete reinforcement rods (pitting corrosion).

5. On the basis of the results obtained under the experimental conditions, equations (2), (4) and (6) were numbered. Therefore, the goodness of fit of these equations is the best in the cases when the composition of reinforced cement-based material and actual conditions are identical with the experimental conditions. These are: cement sand mix ratio of $1: 3$ or ca $500 \mathrm{~kg}$ of cement on $1 \mathrm{~m}^{3}$ of mortar, w/c 0.6 , use of Portland cement with mineralogical composition $\mathrm{C}_{3} \mathrm{~S} 59.0 \%, \mathrm{C}_{2} \mathrm{~S} 14.2 \%, \mathrm{C}_{3} \mathrm{~A} 8.4 \%$ and $\mathrm{C}_{4} \mathrm{AF} 9.8 \%$ (according to Bogue), curing temperature $20^{\circ} \mathrm{C}$. Under these conditions it is possible to calculate the steel corrosion rate as a function of the proportion of $\mathrm{CaCl}_{2}$ in cement-based material in range of 1 to $8 \%$ and of relative humidity. With increasing difference between experimental and actual conditions the goodness of fit of the given equations and the reliability of the calculation decrease.

6. For the validity of the numbered equations the dependence on and sensitivity of the experimental çoefficients to the composition of cement-based materials is important. It is well known that the most important factor in corrosion of embedded steel is the quality of pore structure of cement-based materials. This represents a final result of the used composition and processing. It is evident that the rate of contingent steel corrosion must be considerably sensitive to the used composition and processing and, understandably, so must be the sensitive experimental coefficients in the numbered equations expressing this rate. It can be expected that by using technologies aimed at densifying of pore structure and inhibition of corrosion process (decreasing of $\mathrm{w} / \mathrm{c}$ values, application of plasticizing agents, and the like) the corrosion rate will be decreased. Therefore, it can be expected that the values of experimental coefficients will be changed in proportion to the change of steel corrosion rate and the applied technique of measurement of the quality of pore structure of cement-based materials.

\section{References}

Alekseev S N 1978 Proceedings of Conference Ochrana stavebného diela pred koróziou, Bratislava, p. 56 Atkinson A 1985 The time dependence of $\mathrm{pH}$ within a repository for radioactive waste disposal, Report AERE-R 1177, Harwell Lab., Oxford 
Clifton J R 1991 Proceedings of the 5th International Conference on Durability of Building Materials and Components, Brighton (eds) J M Baker, P J Nixon, A J Majumdar and $\mathbf{H}$ Davies, E and F N Spon (London: Chapman and Hall)

Eurin P 1988 Mater. Struct. 21131

Grunau B 1970 Das Baugewerbe, p. 1340

Jambor J and Živica V 1982 Stavebnicky časopis 30563

Jambor J, Živica V, Vargová M and Bágel L 1983 Stavebnicky časopis 31601

Masters L W 1986 Mater. Struct. 19417

Morinaga S 1991 Proceedings of the 5th International Conference on Durability of Building Materials and Components Brighton, UK (eds) J M Baker, P J Nixon, A J Majumdar and H Davies, E and F N Spon (London: Chapman and Hall) p. 5

Müller F K 1985 Mater. Struct. 18463

Odler I and Gasser M 1988 J. Ceram. Soc. 711015

Tuutti K 1971 Proceedings of RILEM Symposium Quality Control of Concrete Structures, vol. 1, sess. 2-3, Service life of structures, Stockholm

Živica V 1993 Mater. Struct. 26318

CSN 722121 Portland cement (in Czech)

ISO-R 597 Definitions and Terminology of Cements

CSN 721208 Testing sands (in Czech)

ISO/R 697, 1968 Method of Testing of Cements Compressive and Flexural Strengths of Plastic Mortars (Rilem-Cembereau Method)

CSN 411373 Steel 11373 (in Czech) 